\title{
Interview with Leonardo Oliveira Pena Costa
}

\author{
Andrei Pereira Pernambuco ${ }^{1}$
}

${ }^{1}$ Centro Universitário de Formiga (UNIFOR-MG)

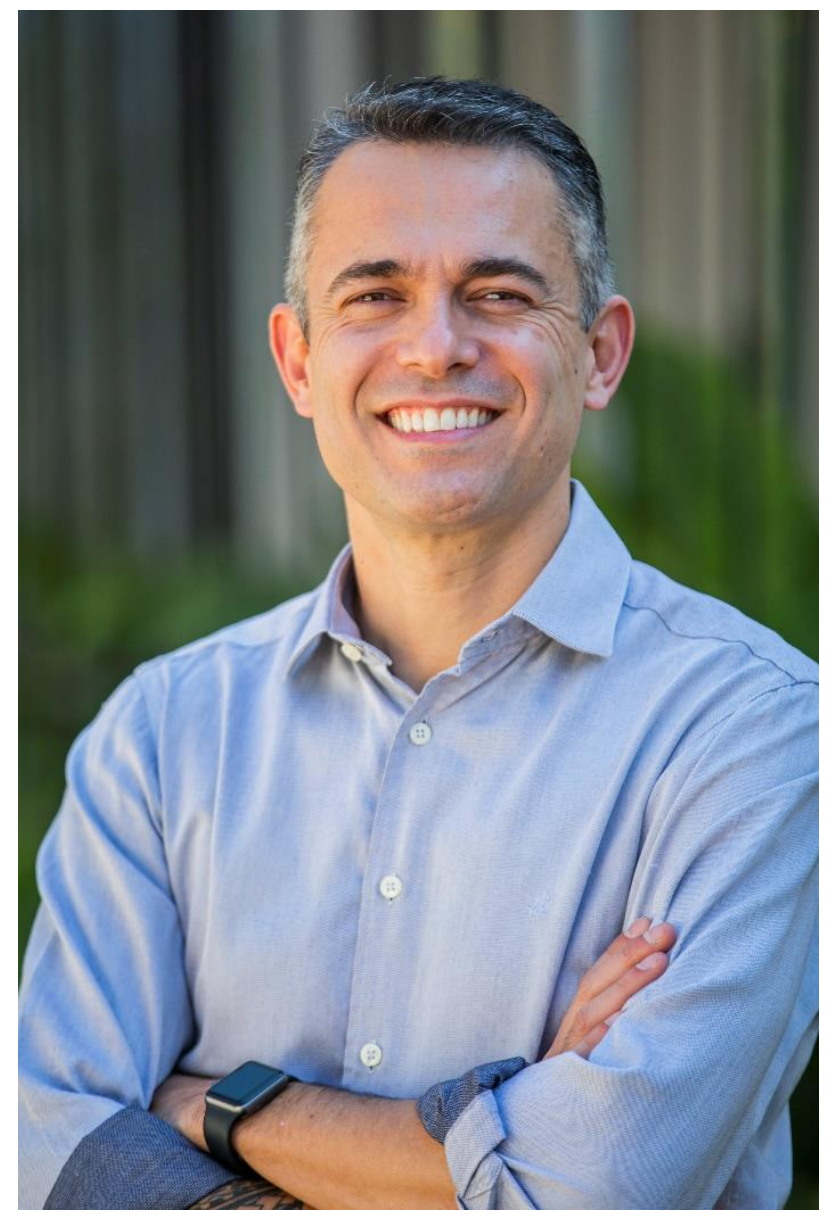

The interviewee for this edition of Conexão Ciência journal is Dr. Leonardo Oliveira Pena Costa, a bachelor of Physiotherapy from the College of Medical Sciences of Minas Gerais, Master of Physical Education from the Federal University of Minas Gerais and PhD in Physiotherapy from the University of Sydney - Australia. His research preferences are studies related to measurement properties of instruments relevant to physiotherapy, evidence-based practice and studies related to patients with low back pain. He was editor-in-chief of the Brazilian Journal of Physical Therapy for four years and associate editor of the Physical Therapy Journal (USA). He is currently coordinator of the Stricto Sensu Program (master's and doctorate level) in Physiotherapy at the University of São Paulo - UNICID. 
1. In Brazil it is impossible to talk about Evidence-Based Practice (EBP) without mentioning Professor Léo Costa. What exactly is EBP? What are its pillars and why is it important for clinicians?

Evidence-based practice is a way of caring for the patient that integrates three inseparably and with equal magnitude components. They are: high-quality clinical evidence (that is, it is not any evidence); the professional's expertise (that is, experience and training are fundamental) and respect for the patient's preferences and beliefs. PBE respects the principles of individuality and complexity of the human being and PBE assumes that all of this together is fraught with uncertainties. These uncertainties make us more humble and work with probabilities: the idea is to offer care with the least probability of error, with the least adverse effects and the lowest cost. Using only isolated components of this PBE triad is a grotesque mistake.

2. Many professionals claim that they do not adhere to EBP, due to the fact that their clinical experience, by itself, demonstrates to them what is effective and what is not. What would be the error in this statement?

As stated above, experience by itself does not guarantee the best care. Experience is obviously important, but basing care solely and exclusively on this pillar will not offer the best solutions for patients. Science evolves, knowledge is changing and standing still in time can have disastrous consequences, in my opnion. Many people forget that changing the clinical picture cannot necessarily be attributed to the care received. In addition, there is an immense memorization bias, in which we remember only the most relevant results that happen in our career. Our brain sucks at aggregating all of our results. Our brain doesn't think in a probabilistic way: it makes (false) causal relationships all the time. The only way to avoid this is by consuming high quality science.

3. Another issue intensified by those who do not use EBP is that, in clinical practice, not only one intervention is used, but a combination of interventions that are aimed at the individuality of the patient. Can this type of situation be replicated in the research? If so, tell us a little bit about it.

This argument makes sense, if viewed superficially. But there are thousands of randomized controlled trials of multimodal interventions. These studies are classified as pragmatic controlled trials. I have no doubt that this can be replicated in research.

4. Whe nusing EBP in clinical reasoning, we must use the best available evidence. Will this always be a systematic review? What are the main methodological designs used in PBE?
The answer is more complex. Whether the clinician wants answers on intervention effects (i.e. whether a treatment works or not); the best option would be to read systematic reviews of the highest quality (such as those of the Cochrane Collaboration, for example). Second would be the high quality Randomized Controlled Trials. I think clinicians should ONLY consume this type of information (initially). By knowing the best, everyone wins.

5. According to your experience, what are the main barriers faced by people who would like to use, but still do not use, EBP?

The first, without questioning, is the language: $91 \%$ of all science on the planet is published in English. This can be easily solved with the Google translator use, for example. The second is more complex: the overwhelming majority of clinicians cannot distinguish good science from bad science. This second problem can only be solved with a lot of study or specialized training. It was based on this statement that I developed the online EBP course for clinicians, which has helped a lot of people to better understand what is good research and what is bad research.

6. Does the fact that an article is published in a good magazine ensures that it is a good article? What would be your main advice for someone who needs to assess the methodological quality of an article?

No. The fact that it is published does not mean anything. There are several aspects, in addition to the quality that justify a publication. I like to make two suggestions: 1) Consume everything published by the Cochrane Collaboration, because the best systematic reviews in the world are there (https://www.cochranelibrary.com); and 2) consume only randomized controlled trials with a score equal to or greater than 6, using the PEDro scale (www.pedro.org.au). Another type of evidence could be consumed in the absence of these two; but try to find those pearls first. This start will help a lot.

7. In a recent search on the Lattes Platform it was possible to verify that you have more than 150 published scientific articles. In this sense, it is observed that in addition to being a great consumer of science, you also produce a lot of quality science. How can experience in research production helps in the training or clinical practice of a professional? Does the concept of "skin in the game" make sense here?

I work on 3 fronts: 1) I have been serving patients since 1999; 2) I produce science and train people (master's and doctoral students) every year and; 3) I teach clinicians how to use the best science in the care of their patients in face-to-face courses, lectures, in social networks or in my online course http://leocostapbe.com.br 
By doing all this, I am able to teach clinicians to use the best evidence in caring for their patients because I also do this in my 21-year career. I think that the concept of "skin in the game" fits well, in my view.As I work with science, I am much more used to probabilities than "feeling".

I use numbers for everything. I never go to a pharmacy without first consulting the evidence of what a doctor has prescribed for me or my children and my wife. I question health professionals if what they offer to me and the people I love is scientifically supported. I don't play with people's health. Our body is our home, we need to take good care of it.

8. You lived in Australia for a few years, during your doctorate course. Many readers of Conexão Ciência Journal wish to live academic experiences abroad. What could you say to them?

I went abroad in 2005. I abandoned a very comfortable life, a very stable career and exchanged everything for a CAPES scholarship to live my dream. There was no money, no friends, no Brazilian culture around me for 5 years. But I can say that it turned me into someone else. It was the best personal experience I've ever had.

I think a full doctorate abroad is not for everyone. It is very demanding and mentally challenging. But I confess that it was extremely fun for me. I was lucky to have an amazing wife by my side (she also did a doctorate there) and it helped a lot. Another factor was the right choice of the University and the advisor: I spent almost 5 years alongside the best in the world in my field. It made all the difference for me.

9. Still in the context of academic experiences, as a physiotherapist and teacher, would you recommend that a newly graduated student seek to enter master's / doctoral programs? Or would you make this recommendation only for those who have graduated a long time ago and who have a certain clinical experience? Does this recommendation apply only to those who are interested in teaching and research careers?

Brazil has one of the worst critical mass indicators on the planet. We have a lower number of doctors / population than several countries in Latin America, Asia and Africa. It is obvious that we need more masters and doctors in the country. People who do master's and doctoral degrees think differently, as simple as that. These can be influencers at any level, whether academic or not.

My wife did a direct doctorate: she graduated and went to the doctorate at a very young age. I entered the doctorate at the age of 29 (with six years of graduation). I have students aged between 22 and 40 years old. The timing for this does not exist. It is up to the individual to decide. In particular, I prefer younger students (because they have more time and will enjoy it more), but this is completely personal.

Masters and doctorates are not exclusive to the academic world. There are hundreds of doctors in clinics and management that help the country to grow and develop. To think that a doctorate and master's degree serves only the academy is inappropriate, in my view.

10. For people who intend to start a master's / doctoral program, what would be your main tips? Please leave a positive message for our readers, especially those who wish to excel in clinical practice or science.

Look for the BEST advisor. The supervisor is above the institution. Try to do it on a theme that, in fact, fascinates you. Do not accept any offer, any project. Try it first! Go to adviser group meetings. Talk to his students (and alumni). Read his publications. The master's and doctorate is a marriage between student and advisor. It's better if the wedding is fun, right?

I had excellent mentors. But I thoroughly investigated the lives of these guys. My experience was better than I imagined. It was worth every second! :) 